\title{
Contents and Construct of Subjective Enjoyment of Community-dwelling Elderly People Performing Physical Activities
}

\author{
Masahide Yajima, RPT, MS ${ }^{1)}$, Yasuyoshi Asakawa, RPT, $\mathrm{PhD}^{1)}$, \\ Haruyasu Yamaguchi, MD, $\mathrm{PhD}^{1)}$ \\ 1) Laboratory of Haruyasu Yamaguchi, Rehabilitation Science, Graduate School of Health Sciences, \\ Gunma University: 3-39-22 Showa-machi, Maebashi, Gunma 371-8514, Japan. TEL: +81 27-220- \\ 8966, FAX: +81 27-220-8966, E-mail:m10704016@gunma-u.ac.jp
}

\begin{abstract}
Purpose] Social participation and physical activities are important for elderly people to extend their healthy life expectancy. It is necessary to feel subjective enjoyment in order to continue a healthy life. While the enjoyment of a psychosocial situation has been reported, the enjoyment of elderly people in continuing social participation and physical activities is unknown. The purpose of this study was to clarify the contents of subjective enjoyment of elderly people and the construct of enjoyment. [Subjects] The subjects were 412 community-dwelling elderly people. [Methods] We asked 412 elderly people about their kinds of subjective enjoyment and reasons for this enjoyment, using our original questionnaire. Data were analyzed using confirmatory factor analysis to evaluate the model fit for enjoyment using parameters of the chi-square value $\left(\chi^{2}\right)$, Goodness of Fit Index (GFI), Adjusted Goodness of Fit Index (AGFI), Comparative Fit Index (CFI), and Root Mean Square Error of Approximation (RMSEA). [Results] The most common item of enjoyment was karaoke. Three factors of activity were "Cognition \& Tasks", "Self-Assertiveness Social Relations", and "Emotions". The model fit met acceptable levels. [Conclusion] Elderly people expect to continue social participation and physical activities incorporating these 3 factors into their activities. Key words: Community-dwelling elderly people, Enjoyment, Construct
\end{abstract}

(This article was submitted Sep. 14, 2012, and was accepted Oct. 19, 2012)

\section{INTRODUCTION}

In a super aging society, social participation and physical activities are important for elderly people to extend their healthy life expectancy. It is necessary to feel subjective enjoyment in order to continue a healthy life ${ }^{1)}$. Several studies have been made of enjoyment ${ }^{2-4)}$. There are some pleasures that old people may still enjoy ${ }^{2,3}$. If we can learn more about activities that are enjoyable, we may find clues about a form of motivation that could become an extremely important human resource ${ }^{4)}$. While the enjoyment of a psychosocial situation has been reported, the enjoyment of elderly people in continuing social participation and physical activities is unknown.

Our previous study tried to clarify reasons for the subjective enjoyment of activities ${ }^{5}$. The subjects were 165 elderly people recruited from 2 districts in Maebashi city and Yoshioka town, Gunma. Using a questionnaire we developed ourselves, we asked about age, gender, the existence of enjoyment, and the reasons for subjective enjoyment in faceto-face interviews. For those who answered "yes" to "the existence of enjoyment", we enquired about the contents and reasons for that subjective enjoyment. Referring to the Taxonomy of Human Goals"), we elicited "yes" or "no" responses to reasons for subjective enjoyment. We performed exploratory factor analysis of the 24 items cited as reasons for subjective enjoyment. The results showed that 159 elderly people (96.4\%) experienced enjoyment, and the main contents were karaoke, going out, conversation, hot spas, and handicrafts. As reasons for subjective enjoyment, we identified 3 factors composed of 11 items. Factor 1 was composed of exploration, understanding, intellectual creativity, mastery, and task creativity. Factor 2 was composed of individuality, self-determination, and superiority; and Factor 3 was composed of tranquility, happiness, and physical well-being. We named them "Cognition \& Tasks", "Self-Assertiveness Social Relations", and "Emotions", respectively. "Cognition" refers to different kinds of mental representations that people may want to construct or maintain. "Tasks" represents desired relationships between the individual and various objects in the environment. "Self-Assertiveness Social Relations" represents the desire to maintain or promote the self. "Emotions" represents different kinds of feelings or emotions that a person may want to experience or avoid. This pilot study indicated that enjoyment could be expressed by these 3 factors. However, the discussion was limited because the test population included only 165 people from 2 similar districts in Maebashi city and Yoshioka town.

This study covered a wider area and larger number of subjects. The purpose of this study was to clarify the contents of subjective enjoyment among community-dwelling elderly 
Table 1. Enjoyment 11

\begin{tabular}{llll}
\hline \multirow{2}{*}{ Emotions } & 1. Tranquility: Feeling relaxed and at ease & Yes & No \\
& 2. Happiness: Experiencing feelings of joy, satisfaction, or well-being & Yes & No \\
& 3. Physical Well-Being: Feeling healthy, energetic, or physically robust & Yes & No \\
\hline \multirow{5}{*}{ 4. Exploration: Satisfying one's curiosity } & Yes & No \\
& 5. Understanding: Gaining knowledge & Yes & No \\
& 6. Intellectual Creativity: Avoiding mindless or familiar ways of thinking & Yes & No \\
& 7. Mastery: Meeting a challenging standard of achievement or improvement & Yes & No \\
& 8. Task Creativity: Engaging in activities involving artistic expression or creativity & Yes & No \\
\hline \multirow{2}{*}{ Self-Assertiveness } & 9. Individuality: Avoiding similarity or conformity with others & Yes & No \\
Social Relations & 10. Self-Determination: Avoiding the feeling of being constrained, or coerced & Yes & No \\
& 11. Superiority: Comparing favorably to others in terms of winning, or success & Yes & No \\
\hline
\end{tabular}

Items 1 to 3 were "Emotions" factors. Items 4 to 8 were "Cognition \& Tasks" factors. Items 9 to 11 were "Self-Assertiveness Social Relations" factors

people, and to examine the validity of the three previously derived factors of subjective enjoyment, "Cognition \& Tasks", "Self-Assertiveness Social Relations", and "Emotions" using confirmatory factor analysis.

\section{SUBJECTS AND METHODS}

A total of 412 elderly people were recruited from 8 districts of Maebashi and Takasaki cities, in the central area of Gunma prefecture. Subjects were able to communicate, and were physically unimpaired people aged over 65 (mean $\pm \mathrm{SD}, 76.1 \pm 6.5$ years). The questionnaire contained 11 questions.

Reasons for subjective enjoyment were assessed using our original questionnaire named "Enjoyment 11" (Table 1). We asked subjects about the existence of enjoyment, kinds of enjoyment, age, gender, the presence of pain and its location, walking distance without a rest, and subjective well-being in face-to-face interviews. For answers to the 11 items, we replaced "yes" and "no" with " 1 " and " 0 ", respectively, and performed confirmatory factor analysis (CFA) to evaluate the model fit for enjoyment using the chi-square value $\left(\chi^{2}\right)$, Goodness of Fit Index (GFI), Adjusted Goodness of Fit Index (AGFI), Comparative Fit Index (CFI), and Root Mean Square Error of Approximation (RMSEA), in AMOS $17.0 \mathrm{~J}$ (SPSS Inc.).

This study was approved by the Epidemiologic Research Ethics Committee of Gunma University Faculty of Medicine (Approval Number: 23-12), and written informed consent was obtained from all participants.

\section{RESULTS}

The subjects were $161(39.1 \%)$ males and $251(60.9 \%)$ females. Subjects with subjective well-being "enjoying good health" were 302 (79.1\%). Subjects experiencing pain were 220 (53.4\%), with the location of pain being the knee 116 $(28.2 \%)$ and low back $110(26.7 \%)$. For walking distance without a rest, 296 subjects could walk for "1 km or more" $(71.8 \%)$.

For the presence or absence of enjoyment, 15 subjects
Table 2. Subject characteristics

\begin{tabular}{llll}
\hline & & $\mathrm{n}$ & $\%$ \\
\hline Gender & Male & 161 & 39.1 \\
& Female & 251 & 60.9 \\
Enjoyment & Non-existence & 15 & 3.6 \\
Content of enjoyment & & 397 & 96.4 \\
(top 5) & & & \\
& Karastence & & \\
& Dance & 118 & 29.7 \\
& Going out & 62 & 15.6 \\
& Chatting with friends & 48 & 12.0 \\
& Ground-Golf & 33 & 8.3 \\
\hline
\end{tabular}

$(\mathrm{N}=412)$

answered "no" (3.6\%), and 397 subjects answered "yes" (96.4\%). The most common content of enjoyment was karaoke (singing with a recorded accompaniment) 118 (29.7\%), followed by dancing (rhythmic body action for a limited time to promote the transmission of emotion and resolve) $62(15.6 \%)$, going out $48(12.0 \%)$, chatting with friends $40(10.0 \%)$ and ground-golf (a sport invented in Japan for elderly people which involves putting a ball into a post like kago.) 33 (8.3\%). The top 5 contents accounted for $75.6 \%$ of the total (Table 2 ).

The model fit was $\chi^{2}=46.32 \quad(p=0.26), \quad G F I=0.98$, $\mathrm{AGFI}=0.96, \mathrm{CFI}=0.99$, and RMSEA $=0.01$. The model is shown in Figure 1. Significant correlations between "Cognition \& Tasks" and "Emotions" ( $\mathrm{r}=0.68, \mathrm{p}<0.001)$, "Cognition \& Tasks" and "Self-Assertiveness Social Relations" ( $\mathrm{r}=0.54, \mathrm{p}<0.001)$, and "Self-Assertiveness Social Relations" and "Emotions" ( $\mathrm{r}=0.39, \mathrm{p}<0.001)$ were found. All standardized path coefficients from latent variables to observance variables were significant $(\mathrm{p}<0.001)$.

\section{DISCUSSION}

A total of $53.4 \%$ of subjects experienced pain, with 


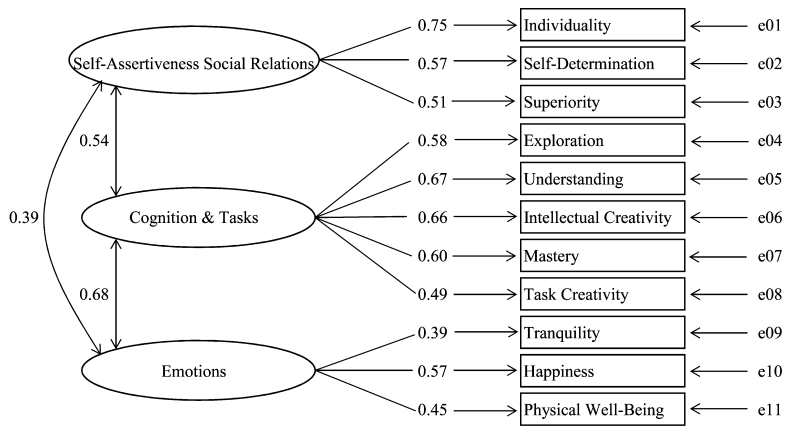

Fig. 1. Model of enjoyment

the location of pain being the knee $(28.2 \%)$ and low back (26.7\%). However, subjects with subjective well-being "enjoying good health" were $79.1 \%$. For walking distance without a rest, $71.8 \%$ subjects could walk "1 km or more". Therefore, we think that the subjects of the present study were active elderly people.

Subjects who answered that they experienced enjoyment accounted for $96.4 \%$, while those who did not were $3.6 \%$. Community-dwelling elderly people experienced a high percentage of enjoyment. The top 5 contents of enjoyment were karaoke, dancing, going out, chatting with friends, and ground-golf. Onishi ${ }^{7)}$ studied 424 older people for activities that contributed to happiness in rural areas in Japan. Activities which created feelings of enjoyment were "bathing", "eating", "watching TV", "conversation with neighbors", and "looking after crafts and the garden". According to an international comparison of Japan, America, Korea, Germany, and France, "spending time with children, grandchildren, and family" was the most-chosen activity in all countries. "Having a meal and chatting with friends" was the second-most-chosen activity in the 4 countries excluding Japan ${ }^{8}$. Compared with the results of this study, a common item was chatting with friends. Therefore, there is a commonality in the enjoyment experienced by elderly people. Additionally, the top 5 contents of enjoyment had high percentages. However, reasons for enjoyment differed among individuals. It is important to know the reasons for enjoyment.

The model fit was $\chi^{2}=46.32 \quad(p=0.26), \quad G F I=0.98$, AGFI $=0.96, \mathrm{CFI}=0.99$, and RMSEA $=0.01$. When GFI approaches 1, the model has skills of description. When AGFI approaches 1, the model has a good fit to the data. When CFI is 0.90 or greater, the model is well-adapted to the data. When RMSEA is lower than 0.05 , the model is a good fit. Therefore, the model fit was acceptable. The model had a construct. The model for males was similar to the model for females in this study. Gender differences might be slight in the construct of enjoyment. Csikszentmihalyi ${ }^{9)}$ performed factor analysis regarding the reasons for enjoyment in individual activities. The extracted factors were "Friendship and Relaxation", "Risk and Chance", "Problem Solving", "Competition", and "Creative". The most prominent common ground was "Creative" and "Problem Solving". Despite the existence of formal differences between activities, all activities gave the emotion of "Designing, Discovering, and Problem Solving" for participants. Compared with this model, "Cognition \& Tasks" shares similarities with "Designing, Discovering, and Problem Solving". "Self-Assertiveness Social Relations" is related with "Competition" through the position of comparison with other people. "Emotions" is related with "Friendship and Relaxation" through the position of relaxation. Subjects of that study were not limited to elderly people. However, there are similarities with our study. Regardless of age, the reasons for enjoyment were essentially the same.

Continuation of social participation and physical activities should incorporate the following 3 factors into each activity. "Approach to Cognition \& Tasks" aims to keep novelty and challenge in personal activities. For example, repeated bodily exercise becomes boring. Therefore, exercise should include a level of difficulty. In this case, it is important to consider worry and fear of the task being too difficult. "Approach to Self-Assertiveness Social Relations" aims to conduct personal activities, to provide a place to introduce activities to another person, having one's place as coach of the activity, and to encourage participation in community activities. "Approach to Emotions" aims to offer many activities relating to feeling relaxed, pleasure, and having good health.

The results of this study indicate that factors of participation in the community with enjoyment are composed of 11 items.

\section{REFERENCES}

1) Japan Health Promotion Fitness Foundation: http://www.kenkounippon 21 . gr.jp/kenkounippon21/about/kakuron/index.html, (Accessed Aug. 10, 2012) (in Japanese).

2) Powell JG: Commentary. In: Cicero Cato Maior De Senectute: first paperback edition. Cambridge: Cambridge University Press, 2004, pp 93-266.

3) Cicero MT: Cato Maior De Senectute: second edition. Yagi S, Yagi A (trans.), Kyoto: Hozokan, 1999, pp 50-74.

4) Csikszentmihalyi M: Enjoyment and intrinsic motivation. In: Beyond Boredom and Anxiety; Experiencing Flow In Work and Play: 25th anniversary edition. San Francisco: Jossey-Bass Publishers, 2000, pp 1-12.

5) Yajima M, Asakawa Y, Yamaguchi H: Structural factors of "enjoyment" among community-dwelling elderly. Rigakuryoho Kagaku, 2011, 26: 95-99 (in Japanese). [CrossRef]

6) Ford ME: Personal goals. In: Motivating Humans; Goals, Emotions, and Personal Agency Beliefs. Newbury Park: SAGE Publications, 1992, pp 83-122.

7) Onishi J, Masuda Y, Suzuki Y, et al.: Activities contributing to happiness of older adults in rural communities. Nihon Noson Igakkai Zassi, 2004, 53: 641-648 (in Japanese).

8) Cabinet Office, Government of Japan: http://www8.cao.go.jp/kourei/ishiki/h17_kiso/pdf/youyaku.pdf (Accessed Aug. 10, 2012) (in Japanese).

9) Csikszentmihalyi M: Structure of autotelic activities. In: Beyond Boredom and Anxiety; Experiencing Flow In Work and Play: 25th anniversary edition. San Francisco: Jossey-Bass Publishers, 2000, pp 24-34. 